\section{EDUCACÃ̃O}

V.8 • N.3 • Publicação Contínua - 2020

ISSN Digital: 2316-3828

ISSN Impresso: 2316-333X

DOI: 10.17564/2316-3828.2020v8n3p627-643
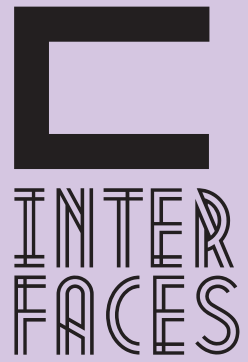

CIENTÍFICAS

\title{
FAMÍLIAS E ESCOLA EM TEMPOS DE PANDEMIA: FACES DAS DESIGUALDADES EDUCACIONAIS EM POSTAGENS DO FACEBOOK
}

\section{FAMILES AND SCHOOL IN TMES OF PANDEMIC: FACES OF EDUCATIONAL INEQUALITIES INFACEBOOK POSTS}

\section{FAMLLIAS Y ESCUELA EN TIEMPOS DE PANDEMA: LAS CARAS DE LAS DESIGUALDADES EDUCATIVAS EN PUBLLCACIONES DE FACEBOOK}

\section{RESUMO}

A pandemia do coronavírus desvelou a face mais perversa da desigualdade socioeconômica vivida mundialmente por milhares de pessoas. No campo da educação, os desafios impostos ao acesso e permanência escolar foi ainda mais impactante para famílias pobres que vivem em territórios de vulnerabilidade, sem acesso às tecnologias para aulas virtuais. A partir de metodologia qualitativa do tipo exploratória, esse trabalho teve o objetivo de analisar o discurso social a respeito dos impactos da pandemia no campo da educação a partir de imagem de um post "viralizado" e os comentários gerados na rede social Facebook sobre o assunto. Os dados analisados reforçam ideias generalizadas e preconceituosas sobre as famílias pobres em sua tarefa de educar, ora culpabilizando crianças, ora pais e professores, naturalizando a complexidade do sistema público de educação e, reforçando pensamentos pautados numa ideologia neoliberal meritocrática.

\section{PALAVRAS-CHAVE}

Coronavírus. Família-escola. Vulnerabilidade. Desigualdades. 
The Coronavirus Pandemic has unveiled the most perverse face of socioeconomic inequality experienced by thousands of people worldwide. In the field of education, the challenges imposed on access and school attendance were even more impactful for poor families living in vulnerable territories, without access to technologies for virtual classes. Using an exploratory qualitative methodology, this work aimed to analyze the social discourse regarding the impacts of the pandemic in the field of education from the image of a "viralized" post and the comments generated on the social network Facebook on the subject. The analyzed data reinforce widespread and prejudiced ideas about poor families in their task of educating, sometimes blaming children, sometimes parents and teachers, naturalizing the complexity of the public education system and reinforcing thoughts based on a meritocratic neoliberal ideology.

\section{KEYWORDS}

Coronavirus. Family-school. Vulnerability. Inequalities

\section{RESUMEN}

La pandemia de coronavirus ha revelado la cara más perversa de la desigualdad socioeconómica vivida por miles de personas en todo el mundo. En el campo de la educación, los desafíos impuestos al acceso y la permanencia escolar fueron aún más impactantes para las familias pobres que viven en territorios vulnerables, sin acceso a tecnologías para clases virtuales. Usando una metodología cualitativa exploratoria, este trabajo tuvo como objetivo analizar el discurso social sobre los impactos de la pandemia en el campo de la educación a partir de la imagen de una publicación "viralizada" y los comentarios generados en la red social Facebook sobre el tema. Los datos analizados refuerzan ideas generalizadas y prejuiciosas sobre las familias pobres en su tarea de educar, a veces culpando a los niños, a veces a los padres y maestros, naturalizando la complejidad del sistema de educación pública y reforzando pensamientos basados en una ideología neoliberal meritocrática.

\section{PALABRAS CLAVE}

Coronavirus. Familia-escuela. Vulnerabilidad. Desigualdades

Interfaces Científicas - Aracaju • V.8 - N.3 • p. 627 - 643 • Publicação Contínua - 2020 


\section{INTRODUÇ̧̃̃o}

A Pandemia do novo coronavírus revelou a face mais cruel da desigualdade presente no planeta. No Brasil, não foi diferente dada as suas condições geográficas e políticas, milhões de brasileiros entraram para as estatísticas aterradoras provocadas pelo imenso abismo social e econômico que ao longo da história do país foi se colocando entre os mais ricos e os mais pobres. Estima-se que milhares de famílias que vivem em condições de vulnerabilidade poderão sucumbir à doença e a falta de suprimentos essenciais, tais como água potável, saneamento básico e alimentação. Não há como prever todos os impactos, contudo já temos dados para análises dramáticas no campo da saúde, do trabalho e da educação.

No momento em que a população é orientada a permanecer em isolamento social, em que trabalhadores não podem mais ocupar seus postos de trabalho, crianças e jovens estão proibidos de frequentar a escola e os hospitais começam a ficar sobrecarregados de pessoas gravemente enfermas, a distância social e as diferenças de classe, de gênero e de raça se revelam aterradoras. Nessa conjuntura, os espaços e o papel da família e escola aparecem como contextos de análise nas suas inter-relações, sobretudo, nas diferenças descortinadas a partir da existência cotidiana das classes dominantes e das minorias (pobres, favelados, negros etc.).

A ideia inicial de que a pandemia seria democrática, atingindo igualmente a ricos e pobres foi desmascarada pela realidade atroz, demonstrando que aqueles que têm mais acesso à bens e serviços de saúde acabam, mais uma vez, se beneficiando. Dessa forma, descobriu-se que "o coronavírus não é democrático. Dependendo da sociedade e da sua forma de organizar a vida social reproduz a lógica classista, excludente e seletiva do capitalismo" (DORNELLES, 2020, p. 101).

O isolamento social recomendado pela Organização Mundial da Saúde (OMS)

como medida para o combate ao vírus, responsável pelo número crescente de mortes em todo o mundo tem ocasionado repercussões extremamente negativas para todas as sociedades. Neste cenário, para a maioria da população que vive em situação de vulnerabilidade social, esses impactos podem ser maiores quando pensamos no cotidiano de mulheres e crianças em situações adversas, vitimizadas por processos gerados por violência doméstica.

Estudos de Melo e outros autores (2020) evidenciam que a violência e o abuso infantil crescem nas ocasiões em que há o encerramento de atividades escolares com características que podemos associar à pandemia da COVID-19. "O fechamento de escolas e outras organizações comunitárias têm limitado a capacidade dos principais parceiros das comunidades em detectar e denunciar abusos" (MELO et al., 2020, p. 6).

No Brasil, a orientação do Ministério da Educação para todas as modalidades de ensino é observada na pressão pela implantação massiva da modalidade de Educação à Distância (EAD) ou "ensino remoto". Tal prerrogativa, tem trazido graves consequências para famílias das classes mais vulneráveis da população, em que o acesso a internet é algo ainda muito distante de suas realidades. Além disso, há imprecisões sobre como as atividades escolares podem ser realizadas de forma virtual. 0 "ensino remoto" pode ser compreendido como prática improvisada, sem preparo e planejamento, realizada "a toque 
de caixa pelas Secretaria de Educação com o intuito de atender demandas educacionais imediatas que surgiram com o fechamento das escolas na pandemia da COVID-19” (FRANÇA FILHO et al., 2020, p. 27).

Sobre as questões que envolvem tais práticas, permeadas pela exclusão digital de estudantes das classes subalternizadas, este trabalho teve o objetivo de compreender como são significadas as relações família-escola em tempos de isolamento social, por meio de análise de material (imagem e textos) compartilhados e disseminados pela rede social Facebook.

\section{ACESSO A INTERNET PELAS FAMÍLIAS BRASILEIRAS}

A revolução tecnológica pela qual o mundo tem passado nas últimas décadas transformou as formas de comunicação, transmissão e construção de conhecimento em proporções nunca vistas na histórica da humanidade. Tal revolução teve influências diretas e indiretas nos setores socioeconômicos, ampliando e modificando as referências de consumo e, produzindo mudanças significativas nos modos de ensinar e aprender. Contudo, o modelo de educação formal ainda continua a vigorar ao redor do mundo, com estudantes, aprendendo como seus pais e avós aprenderam. Nesse formato educacional sistemático, a presença de professores e alunos, lotando salas de aulas de escolas, ainda ocupa a maior parte da vida de crianças e jovens.

Indubitavelmente a propagação da internet favoreceu as mais diversas formas de interação social e econômica, oportunizando a comunicação entre pessoas nos locais mais inóspitos e afastados do globo, diminuindo distâncias linguísticas e culturais. Entretanto, isso não se deu para todos e em todos os países. Moreira e outros autores, (2019) assinalam a importância de políticas públicas de inclusão digital com ações que beneficiem a população em condição socioeconômica inferior, no acesso democrático às tecnologias digitais.

Embora, ao longo das últimas décadas, tenha ocorrido a ampliação ao acesso à internet pelo mundo, o seu uso está intimamente ligado às diferenças socioeconômicas de cada espaço geográfico. Desse modo, ao tratarmos desse fenômeno, é importante considerar diferenças regionais, culturais, políticas e sociais, ponderando que em países onde há maior concentração de riqueza, encontramos maiores índices de usuários da internet, diferentemente dos países mais pobres em que tal acesso é restrito e multideterminado por fatores histórico-culturais (OLIVEIRA, 2017; FRAGOSO et al., 2011).

Um levantamento recente da Pesquisa Nacional por Amostra de Domicílios (PNAD) do Instituto Brasileiro de Geografia Estatística (IBGE, 2018) apontou que ainda há uma grande parcela de brasileiros que não tem acesso à internet em suas residências. A pesquisa registrou que um em cada quatro brasileiros não possui tal acesso. Isso representa um total de aproximadamente 46 milhões de pessoas sem acessar a rede no país. A proporção muda exponencialmente a depender da região geográfica.

Os motivos da exclusão digital podem variar entre os altos preços das taxas de serviços, falta de disponibilidade de rede ou pelo alto custo de equipamentos eletrônicos. 0 estudo ainda mostra que a posse de Microcomputadores e tablets para muitas famílias é quase impossível, dada as suas condições de subsistência. A média de renda per capita de cada família é um importante 
indicador para compreensão sobre a presença de equipamentos eletrônicos e sobre o acesso a serviços de internet no país.

Nessa conjuntura, configuram-se as especificidades da demanda ocasionada pela pandemia do COVID-19 e a totalidade de escolas brasileiras que, seguindo o exemplo de outros países, implantou na pandemia, de forma aligeirada o "ensino remoto" para alunos de todas as modalidades de ensino em todas as regiões do país.

\section{METODOLOGIA}

Este trabalho de caráter qualitativo e exploratório teve o objetivo de analisar e discutir como as relações família-escola em tempos de pandemia do coronavírus são significadas em postagem e nos comentários no Facebook. Optou-se pela de coleta de dados em rede social, por entender que tal perspectiva possibilita o acesso de informações com potencialidades para a análise de discursos individuais e grupais, representações e interações multideterminadas sobre uma realidade social, geograficamente situada e historicamente datada.

$\mathrm{Na}$ atualidade, redes sociais como o Facebook [https://www.facebook.com/] têm se configurado como um campo fértil para pesquisa, em que o pesquisador pode encontrar representações sociais sobre vários assuntos a partir de opiniões, crenças, saberes, ideologias e sentimentos discutidos e compartilhados por bilhões de usuários. Nesse contexto encontram "pessoas comuns, utilizando linguagens cotidianas, trocando opiniões e construindo suas visões e discursos sobre o poder político e sobre os diversos fatos que afetam suas vidas" (SILVEIRA, 2015, p. 1638).

A coleta de dados empreendidas neste trabalho seguiu as considerações de Fragoso e outros autores (2011) as quais assinalam que cabe ao pesquisador realizar a seleção do momento e das variáveis que serão analisadas, de acordo com a problemática que se pretende investigar. Nesse caminho, a busca pelos dados se deu em comunidades do Facebook, a partir de uma imagem "viralizada" na rede social e em seus respectivos comentários que traziam discussões sobre a família pobre, a escola e o "ensino remoto" em tempos de isolamento social.

\section{ANÁLISE E DISCUSSÃO DOS RESULTADOS}

A análise dos dados incidiu sobre as discussões implícitas e explícitas nos comentários (sem identificação dos autores) sobre a imagem que ganhou destaque ao aparecer na rede social e no WhatsA$p p$ em abril de 2020. Tanto a origem, quanto a autoria da figura é desconhecida, mas foi detectada a mesma postagem em países da América Latina. No Brasil, até o momento dessa pesquisa, o post já contava com 29 mil reações, 32.245 mil compartilhamentos e 818 comentários dos internautas. 
Figura 1 - Imagem do Facebook: família pobre com seus filhos em uma moradia de apenas um cômodo

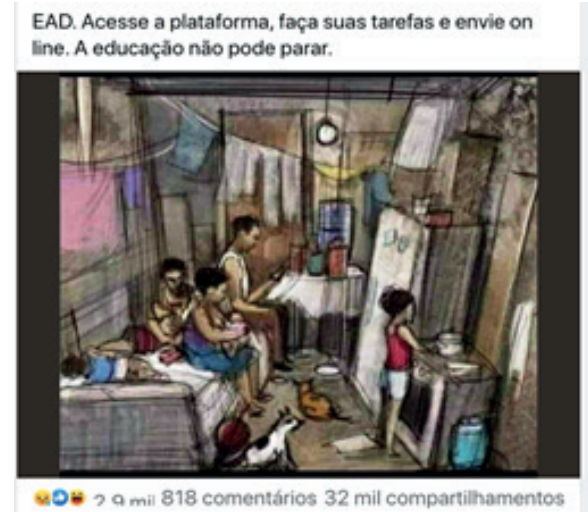

Fonte: Facebook (http://www.facebook.com/)

A análise inicial dos 818 comentários ocorreu no sentido de separar somente os que se referiam a família e a escola. Descartamos a posteriori, os comentários repetidos ou relativos a discussões sem relação como o objeto estudado. A amostra final se constitui de 70 posts, dos quais extraímos alguns excertos para a discussão.

\section{PRECONCEITO CONTRA A FAMÍLIA POBRE: A HISTÓRIA SE REPETE}

A família pode ser entendida como uma categoria com múltiplas compreensões. Há muitas formas de arranjos familiares que se constituíram historicamente nas últimas décadas no Brasil e no mundo. Os estudos sobre essa temática dão ênfase a família contemporânea a partir de suas várias possibilidades de educar e cuidar de crianças, jovens e idosos em diferentes conformações, assinalando a sua desconstrução como instituição naturalizada, com padrões normatizadores (MATA et al., 2017; BIROLI, 2014).

A análise inicial da imagem, objeto desta pesquisa, nos lembra à realidade de famílias que vivem em territórios de vulnerabilidade nas periferias metropolitanas. Como um gatilho para disparar o debate foi acrescentada a frase: "Acesse a plataforma, faça suas tarefas e envie on line. A educação não pode parar”, o que imediatamente nos remete aos problemas enfrentados pelos mais pobres para acessar a internet e frequentar as atividades escolares virtuais. Porém, contrariando essas primeiras impressões, observamos um elevado número de comentários pautados no preconceito histórico contra as famílias das classes menos favorecidas, gerando discussões sobre o número de filhos dessas famílias, planejamento familiar, controle de natalidade, vitimização de famílias pobres e culpabilização de pais e mãe do sucateamento da escola pública.

Sobre o preconceito contra os miseráveis, Nascimento, Cunha e Vicente (2007) discutem a forma como historicamente as práticas de desqualificação da família pobre tem acompanhado os estudos 
desse campo, incluindo os modos e processos de criminalizar a pobreza e desqualificar a população pobre no Brasil, em sua origem. Os comentários do Facebook nos levam a pensar na perspectiva apontada pelas autoras:

[...] pobre é burro cara... não tem dinheiro e não se previne... quer ter 10 filho pra ter bolsa família e dps sobra pra qm ? pros proprios filhos..."

A família sem condições, mas na quantidade de filhos estão em dia né? Aff”

[...] parece que quanto mais pobre a pessoa é mais filho tem. Gente! camisinha e de graça no postinho/estações.

Outros comentários rechaçam discursos preconceituosos relativos à família, número de filhos e os benefícios sociais oferecidos à população mais pobre.

Tem gente que ainda compra esse discursinho de que as pessoas fazem filho por conta do Bolsa Família. 0 valor do Bolsa Família para quem se encontra em extrema pobreza é de 89 reais. Você só pode acumular 5 benefícios chegando ao valor máximo de 205 reais. Quem é que sustenta uma família com 205 reais? Essa galera não tem noção de nada mesmo!

Esses excertos assinalam como as práticas discursivas em relação à família a responsabiliza pela sua pobreza, num perverso ataque à sua incapacidade de controle da prole, num processo acusatório de uso indevido e abusivo de benefícios sociais como o "Bolsa família". Outros criticam tais arranjos familiares pela suposta falta de interesse pela escola e futuro dos filhos:

[...] morei em barraco de madeirite, em invasão metade da minha vida. A única coisa que me salva é não ter tido filho e estudar relativamente bastante. A questão aqui é socioeconômica, porém só quem tá dentro da situação pode mudar. O governo não pode esterilizar em massa mulher/homem a partir de x filhos. Mas a família precisa ter noção de que não dá para ter muitos. Mas olha o exemplo da gravura... É uma escadinha.

Comentários como esses assinalam histórias de vida de pobreza e adversidades, contudo sem redimir a família da culpa pelos seus infortúnios. Ainda que a postagem tenha sinalizado a educação como única possibilidade de melhoria na qualidade de vida de um indivíduo, apresenta uma visão de família pautada na responsabilização social e na lei do próprio esforço. Nesse caso, a família aparece como culpada por ser pobre, por ter muitos filhos e ser desprovida de recursos intelectuais para se organizar economicamente, como sugerem estudos de Mata e outros autores (2017, p 10) apontando "a família pobre como culpada pela situação em que se encontram seus filhos", que negligencia na quantidade da prole e maltrata suas crianças, quando não é capaz de lhe assegurar condições adequadas de existência. Discursos como esses eximem o Estado, o sistema público e a sociedade de suas responsabilidades: 
[...] é aquelas famílias nessa condição que não querem trabalhar, não querem a estudar, não querem se esforçar, os pais banalizam os estudos e querem mesmo é receber dinheiro do governo, que fazer?"

[...] o fato é que a culpa é do pai e da mãe, irresponsabilidade e falta de vontade (porque quem quer de verdade, sempre dá um jeito, vide as histórias de pessoas que alcançaram seus sonhos mesmo com diversas dificuldades)

[...] a imagem mostra 5 crianças em um cômodo, em uma casa não confortável que me faz pensar que os principais culpados não são a sociedade não são o governo (embora ele tenha a parcela de culpa) mais os maiores culpados são os pais. Sem condições tiveram um monte de filhos.

A maior parte dos comentários sobre as famílias pobres tende a colocar essa população a margem da sociedade, não considerando a forma histórica com que foi distanciada de seus direitos e benefícios do sistema capitalista. Muitas dessas pessoas encontram-se invisibilizadas em cadastros do sistema público, por falta de registros de nascimento ou de documentos que teriam direito como cidadãos. As deficiências da família atribuídas à pobreza aparecem em discussões relacionadas às possíveis soluções de problemas sociais no Brasil, que vão desde o acesso à educação até a esterilização da população pobre, para o controle de natalidade.

Creio que deveria ser mais fácil o acesso a laqueadura e tivesse mais campanha e informações sobre o procedimento assim também como a vasectomia. Apesar de já existir o procedimento o acesso é muito difícil e a informação não chega a muitas famílias. Muitas pessoas não querem ter muitos filhos e acabam tendo, mas dizer que não se deve ter medidas para que pare isso é ignorância, as crianças sofrem. Todas devem ter acesso a uma boa educação e uma condição de vida básica no mínimo e infelizmente muitas não tem por conta dos próprios pais, não por quererem isso para o próprio filho mas por não ter condições de se prevenir e por falta de informação.

Outros comentários contextualizaram a questão da família pobre e a falta de informação e de acesso à educação, rechaçando explanações preconceituosas.

[...] Essa brincadeira é um pouco superficial, dado o cenário econômico e social que esse tipo de família retratada na imagem tem. Lembrando que a população carente não tem o mesmo acesso a informação sobre prevenção que você. Não adianta falar que tudo está na internet, pois muitas vezes também não têm nem saneamento básico, que dirá internet móvel ou fixa na casa. Antes de julgar a quantidade de filho que as pessoas têm, tente entender o contexto que elas vivem.

Estudos têm demonstrado a relação entre taxas de natalidade de famílias pobres e a baixa escolaridade de pais e mães. Nesse ciclo, a probabilidade ou a suscetibilidade de uma criança reproduzir 
a realidade socioeconômica de seus progenitores também é bastante alta (LAZARETTI et al., 2019; BRITO, 2008). Nesse prisma, muitos comentários atribuem o fracasso escolar das crianças, ao local de moradia e aos modos de vida das famílias em situação de vulnerabilidade. Esses discursos fazem inferências sobre a miséria, caracterizando essas famílias como perigosas, fadadas à criminalidade e desqualificadas para o cuidado de seus filhos. Nela depositam-se atributos como "desestruturada, incompetente, fracassada, delinquente", dentre outras qualidades inferiores, concebendo, por fim, "os pobres como necessitados de intervenções de especialistas que venham regular e tutelar suas vidas” (MATA et al., 2017, p. 12). Contrariando essas prerrogativas, algumas postagens da rede social, advogam em favor dessas famílias:

[...] acham que o pobre faz mais filhos pq quer, pq acha legal um monte de criança passando fome. Quando a gente fala em educação sexual, vem um monte de gente dizer que não é necessário, mas esses são os primeiros a questionar o pq o pobre tem tanto filho. [...] tenta entender que nem todo mundo tem acesso a informação que você tem! Falar pra usar preservativo é muito fácil, como se fosse $100 \%$ eficaz. Existem realidades diferentes, que a gente só enxerga se quiser e quando para de olhar pro próprio umbigo.

A forma como as famílias pobres têm sua imagem analisada no Facebook tem a ver com o lugar que foi historicamente desenhado para essa população. Desse modo, podemos afirmar que tal forma de "olhar de cima" para os pobres, corresponde a esses lugares pré-determinados e ocupados por pessoas que realizam as tarefas mais rudes, em ocupações consideradas menos qualificadas, sem que para isso sejam necessários longos anos de estudo.

Parte de nosso atraso como nação vincula-se diretamente a esse imaginário, na maioria das vezes não revelado, de "castas sociais" (MOLL, 2014, p. 17). Hoje sabemos que o acesso dos filhos das classes trabalhadoras aos seus direitos básicos, fundamentalmente à educação, por meio de políticas públicas que permitam o exercício digno da cidadania, é um dos únicos meios capazes de almejarmos um futuro promissor com cenários sociais mais equânimes para todos.

\section{ESCOLA EM TEMPOS DE PANDEMIA: FAMÍLIA POBREZA E MERITOCRACIA}

Desde o começo do isolamento social no Brasil, os veículos midiáticos têm apresentado várias notícias de crianças que vivem em comunidades pobres tentando ter acesso a internet por meio de idas ao comércio local, na casa de vizinhos ou até subindo em árvores na tentativa de se conectar à internet. Para muitas dessas crianças, uma das únicas fontes de interação social tem sido a escola, como aponta um dos internautas: "É duro, e é a realidade de muitas famílias brasileiras, a escola é um refúgio para as crianças”. Outro comentário que sintetiza de forma contundente o que mostra a imagem é o seguinte:

Que plataforma? Tem família que não tem nem o que comer, nem acesso a internet, o certo seria a escola deixar o conteúdo impresso na escola e os pais que tivesse interesse 
fosse até a escola, tem prefeitura dando cesta básica, pq tem criança que vai a escola até mesmo para se alimentar, agora pra muitos é fácil falar.

O comentário em destaque, repercute a imagem analisada e levanta mais uma questão que veio à tona com a epidemia: as dificuldades concretas de existência de famílias em territórios vulneráveis, sem o mínimo para sobreviver. Pela falta de alimentos, muitas das crianças dessas comunidades utilizam os serviços de merenda oferecidos pela escola pública. Em dias de funcionamento da escola, chegam no ambiente da sala de aula, indispostas e em péssimo estado nutricional por não terem se alimentado em suas casas. Essa tem sido uma realidade relatada em estudos sobre identidade da criança pobre, alimentação e direito a educação (SILVA, et al., 2018) ou implicações da merenda no currículo escolar (BEZERRA, 2009), dentre outros. Comentários analisados trazem essa questão:

Triste realidade numa nação, onde milhares de alunos ainda não tem sequer como se alimentar, que dirá o acesso à internet.

Vivemos em mundos diferentes! Na minha realidade os alunos vão a escola principalmente pela merenda, pois para a maioria, essa é a principal ou a única alimentação do dia. Portanto "celular é luxo.E fácil falar pela ótica particular de cada um, difícil é viver a realidade deles. Mais Alteridade por favor!!

Nesses tempos de pandemia, a realidade desses alunos tem aparecido repetidamente nas redes sociais, escancarando as deficiências no campo da saúde pública, principalmente as de ordem sanitária e alimentar, já que muitas dessas crianças vivem em territórios insalubres em que a Covid-19 tende a circular com mais rapidez. Para além da exclusão digital, com o fechamento das escolas, as crianças estão isoladas em locais onde impera toda a sorte de adversidades ambientais, além da violência em que perenemente estão expostas.

[...] tem gente que mora em Barracão e o lugar nem é asfalto, quando chove vira lama... aí se o aluno falta é pq ele não quis ir porque estava com preguiça? o dinheiro da passagem de ônibus dá para matar a fome, da para comprar pão, ou leite, ou bolacha de água e sal... muita das vezes o aluno abandona a escola não é porque quer é porquê não tem condições de continuar ...

[...] a crítica não rola apenas em ter ou não celular/acesso a internet, a ambientação é algo que as vezes pesa muito. Ter que cuidar de casa, irmãos mais novos, enfim...Nem tem estudo de qualidade, com os tiros as escolas fecham, e a mãe que deveria estar em casa muita delas estão dormindo nas casa de patrões. As crianças crescem a mercê da vida ouvindo funk e etc

[...] em comunidades tem tiros e escolas nem sempre funcionam. Já ouviu o som que toca dia e noite nos ouvidos das crianças, sabe como funciona a lei na comunidade? Saiba que muitas crianças são criadas toda vida, sozinhas enquanto as mães empregadas domésticas dormem no emprego. 
Uma outra categoria de comentários se centrou naquilo que a imagem postada busca argumentar: a dificuldade de muitos estudantes pobres em acessar a internet. Assim, aparecem comentários, discutindo a exclusão digital das famílias e a crítica ao Estado como no comentário: "essa é a realidade de muitas famílias. E o governo pensa nelas? A educação EAD só vai reforçar a exclusão...”

Além dos pais não terem computador, nem internet, muitos pais não tem nem formação, são analfabetos ou semi analfabetos e como vão ajudar os filhos. 0 filho não pode sofrer as consequências da irresponsabilidade dos pais.

EAD não é $p$ todos... É artigo de luxo. Que muitos não desfrutam. O ruim é que nem todos tem acesso a net ou redes sociais em nosso país. Ainda há a exclusão digital nessa situação atual, nem todos tem Internet em casa ou está com $\$$ para recarregar o Cel. 0 problema é que nosso país é continental e desigual. Falta também estrutura da família em poder administrar em casa esse aprendizado...

Com uma parcela significativa de famílias excluídas do mercado de trabalho, vivendo na informalidade em comunidades periféricas, o fechamento das cidades e o isolamento social estabeleceu um estado de calamidade que incluiu aproximadamente cem milhões de habitantes. Muitas pessoas perderam suas formas de sustento, tendo de se isolar em suas pequenas moradias insalubres (COUTO et al., 2020). Não demorou para que as desigualdades e as vulnerabilidades dessa população fossem acompanhadas de uma visível exclusão digital, principalmente naquelas famílias em que as crianças deveriam acessar as atividades educacionais de forma virtual. Sobre a virtualização dos processos pedagógicos, a pandemia escancarou duas realidades distintas: a escola para rico e a escola para pobre no Brasil.

Alunos de escolas particulares não possuem problemas para o acesso. Nas escolas públicas o problema no acesso e na aprendizagem vai corroborar para criar ainda mais exclusão.

Minha mãe mora com meu irmão no interior. Até hoje não tem nem computador nem internet lá. Também não existem bibliotecas públicas na cidade. 0 único jeito de acessar a internet é indo na lan house, existem 3 na cidade e a mais próxima de casa não dá pro meu irmão ir sozinho. Agora os dois estão isolados em casa com suspeita de corona. E ai? Como faz esse EaD?

Os comentários mostram que as diferenças sociais, geográficas e socioeconômicas acirraram as desigualdades educacionais, assinalando as limitações de acesso educacionais que atingiram com mais força as crianças de famílias pobres, diferente da realidade das classes sociais mais favorecidas.

[...] A proposta dos governantes é que os jovens estudem a distância pelo celular. Até mesmo dizem que irão conceder pacotes de dados móveis às famílias sem acesso a internet. Porém, só alcança a disciplina escolar do estudo, pelo celular, quem tem acesso a pelo menos um ambiente de estudo (uma vez satisfeitas as necessidades básicas, como se alimentar, por exemplo) [...] a fome e o desemprego voltam a nos assombrar, com condições 
de moradia cada vez mais precárias. Como se apropriar dos conteúdos sistematizados pela humanidade, se essa imposição da educação a distância obriga que os educandos sejam indiferentes às suas experiências de vida [...]

Aqui no Amazonas tem aula em casa em alguns canais de TV passam as aulas, porém os trabalhos são uma zona, muitos não tem facilidade pra criar um PDF e os professores não são preparados pra dar aula nesse formato. Alguns deixaram pra fazer prova quando voltar, outros tão se aventurando em apps que nem sabem usar.

Outra questão importante levantada em alguns comentários, tem a ver com o preparo dos professores para o ensino à distância. Inesperadamente, professores foram obrigados a adaptar suas casas, planos de aulas e estratégias pedagógicas virtuais para efetivar o trabalho docente. Profissionais que nunca tinham usado algumas ferramentas digitais tiveram que se "reinventar", sem preparo e recursos tecnológicos. Alguns, buscaram aprender com seus pares, num processo de improvisação, vivenciando o despreparo e a urgência do trabalho com recursos limitados.

[...] os trabalhos eram passados pelos professores no grupo de WhatsApp a qual todos os alunos tinham acesso, detalhe: escola do estado! Agora tô fazendo um técnico (pelo estado novamente) e todos estão em um grupo com os professores, pois os professores tem uma idade mais avançada e não conseguiram entender o app e nem a gente kkk

Outro comentário responsabiliza professores por atenderem outras demandas não atribuídas ao campo pedagógico, ao mesmo tempo em que aponta a família para a mesma responsabilidade de educar. Para Asbhar e Lopes (2006, p. 68) esse tipo de denúncia se insere na lógica historicamente conhecida de transferir a "culpa" pelo fracasso, que ora é atribuída aos alunos, ora às suas famílias, à figura do educador. Contudo, isso não passa de um "equívoco de natureza ideológica" que encontra eco na retórica de pessoas incapazes de compreender o contexto escolar no bojo "das contradições de uma sociedade de classes”.

[...] professores são uns tolos e pau mandados! Todo mundo manda em professor: psicológico, fonoaudiólogo, médico, supervisão e se deixar até pai de alunos! Vcs tem que para de ficar abraçando causas sociais e atribuir para a família o que é de responsabilidade deles! O professorado já perdeu seu sentido: PEDAGÓGICO! Depois no final do ano não adianta ficar em conselho resmungando pelos cantos da escola que o noinha que quase virou a mão na sua cara o ano todo passou! Cuidem do pedagógico senão todos estão fadados a tomar conta de tudo e por hora não dar conta de nada!

A história parece se repetir, pois, afinal quem são os culpados: a família, a escola, o professor ou o aluno? Há décadas que as classes dominantes destilam críticas perversas pelo fracasso escolar dos filhos das famílias pobres e negras. Entendem que os alunos não aprendem porque sua constituição familiar não é suficientemente adequada para o desenvolvimento psicológico e emocional. "Os pais 
são promíscuos" e em sua maioria violentos, não dão valor para escola e atenção aos filhos. Os professores veem essas famílias como "rudes, desestruturadas, incapazes, perniciosas, muito distantes da concepção burguesa de família sadia” (ASBHAR; LOPES, 2006, p. 64):

Há muitos alunos que não demonstram interesse e nem disciplina. Trabalho numa escola pública (não como professor, mas tenho inúmeras conversas com os professores)... e a conclusão que sempre chegamos é que, na maioria dos casos...a família não acompanha o aluno, deixando-o à mercê da própria sorte... o que se tornará um ciclo vicioso... É um assunto bem complexo... e que não se resolverá em 1 ou 2 anos. A meu ver, deve haver ações dos dois lados [...].

Outra figura que aparece como réu nesse processo é o aluno que segundo Asbhar e Lopes (2006, p. 67) pode ser responsabilizado pelo "seu aparato biológico" ou por pertencer a uma família desestruturada e incapaz. "Ora suas aptidões são insuficientes ou distúrbios psíquicos são produtores do fracasso”. Em outras explicações encontram-se a falta de interesse, de esforço ou de vontade de aprender.

Pobreza não é desculpa, tem gente que passa muita fome e não tem nada, mas faz um esforço tão lindo pra estudar. Tem gente que não tá nem aí.

Lhe convido a vir onde eu trabalho. Alunos depredando todos os materiais escolares fornecidos pelo governo. Realizando guerra de comida, ofendendo professores pois não receberam o mínimo de educação dos pais em casa.

Outro problema somado é que muitos que tem estrutura e acesso a Internet estão com apatia e desinteresse que atinge a juventude no geral nas redes pública e privada.

Os comentários reforçam a ideia de que o problema da educação está nos alunos e reafirma a culpa de pais e mães na ineficácia do trabalho educativo. Apoiam ainda o pensamento que centraliza em pobres e negros da escola pública o mal-estar vivido por uma sociedade desigual. Tal realidade parece não ser reconhecida por um grupo que tem explicações simplistas para a degradação da escola pública brasileira. Assim, as postagens do Facebook são reflexos do pensamento social com discursos que reproduzem uma lógica neoliberal, que vem sendo desmontada pela pandemia e é incapaz de explicar a realidade multideterminada vivida pela maioria da população mais pobre do país. Nessa visão, “o mundo não pode parar" por conta das minorias:

Ninguém esperava isso, mais infelizmente aconteceu, então a gente não pode ficar criticando tudo que o país toma decisão. Por exemplo, tem muitas famílias que não tem internet para estudar, mais as escolas não podem parar de fornecer conteúdo pela internet pq 3/4 não tem, se é que me entende? Estou tentando explicar que ninguém precisa parar a vida por causa de outras pessoas que não tem condições como nós, infelizmente... devemos nos unir agora, e não vitimizar as pessoas. 
Se muitos pensavam que a pandemia teria o poder de humanizar as relações entre as pessoas, os comentários em análise mostram o contrário. Nesse cenário, ainda que as disparidades educacionais sejam ampliadas quando pensamos naqueles que se isolaram em locais inóspitos, o reconhecimento dessa realidade ainda passa pela ideia meritocrática defendida por premissas neoliberais.

Quem quer estudar consegue. Temos Poupatempo, acessa SP, e vários recursos pra se conseguir internet de graça. $O$ problema é que ninguém quer estudar. $E$ isso não é responsabilidade do governo. Esse governo já é extremamente paternalista pra ser de direita porque a população está muito mal acostumada com 16 anos de paternalismo no governo corrupto anterior.

[...] acesse suas aulas através dos postos de internet do governo ou até mesmo vá até a casa de um colega que tenha condições socioeconômicas melhor que a sua e assista as aulas com ele, usando máscara e higienizando as mãos. Não quer né? Entendi...rs

Em meio a tantos comentários, houve diversas discussões que tomaram grande parte das 818 inserções sobre a mesma imagem. Por vezes, algumas ideias preconceituosas foram repelidas por internautas raivosos, custando o bloqueio de alguns perfis pelo Facebook. Alguns conteúdos continham certo sarcasmo e ironia, demonstrando que a rede social abarca toda a sorte de pensamentos e ideologias:

Sim, basta se esforçar que todo mundo chega onde quiser. Se você realmente quiser ser um bilionário, basta usar todos os 30 minutos aos quais você tem direito por acesso nos pontos do poupatempo que você vai ter exatamente a mesma chance de uma pessoa que tem acesso ilimitado no ambiente residencial. Já que todo mundo tá partindo do mesmo ponto, o governo não precisa fazer nada. Certo?

A análise dos comentários é permeada de contradições e deixa a certeza dos efeitos danosos da pandemia em todas as esferas da vida social e econômica mundial, sobretudo na vida das populações marginalizadas. Tais efeitos sobre o campo educacional são preocupantes na medida em que desvelam o escamoteamento das assimetrias históricas vividas pelas escolas feitas para pobres e aquelas destinadas aos ricos no Brasil.

\section{CONSIDERAÇÕES FINAIS}

A pandemia do coronavírus gerou um efeito cascata de proporções nunca vistas na história das sociedades contemporâneas. As consequências negativas do isolamento social atingiram a maioria das atividades humanas, impactando de forma mais aguda as famílias que vivem em territórios vulneráveis.

0 reflexo do discurso social sobre os impactos da pandemia na vida de famílias e escolas brasileiras pode ser compreendido a partir dos comentários gerados em uma postagem de ima- 
gem na rede social, nos possibilitando pensar sobre as condições de escolarização de ricos e de pobres, assim como no preconceito instaurado historicamente aos menos favorecidos economicamente. A análise aqui empreendida nos dá pistas para a compreensão da assimetria socioeconômica e as desigualdades de acesso à escola acirradas e desmascaradas com a pandemia do COVID-19 e o isolamento social.

Embora o estudo considere a subjetividade dos comentários do ambiente do Facebook, assim como a "invisibilidade" dos sujeitos ao tecerem suas opiniões em um espaço público e midiático, a análise nos aponta para um discurso social contaminado por olhares que deslegitimam famílias pobres no trabalho educativo, eximindo o Estado e o sistema público da responsabilidade pelo sucateamento do aparelho educacional em sua ineficácia em educar as camadas menos favorecidas. O debate favorecido pela imagem pouco suscitou indagações sobre a insuficiência e inadequação histórica da escola pública brasileira em atuar junto aos filhos das minorias, transferindo para as famílias a responsabilidade pelo desmonte estratosférico da educação nas últimas décadas no Brasil.

\section{REFERÊNCIAS}

ASBAHR, F. da S. F.; LOPES, J. S. A culpa é sua. Psicologia USP, v. 17, n. 1, p. 53-73, 2006.

BEZERRA J. A. B. Alimentação e escola: significados e implicações curriculares da merenda escolar. Rev Bras Educ., v. 14, p. 103-115, 2009.

BIROLI, F. Família: novos conceitos. São Paulo: Fundação Perseu Abramo, 2014.

BRITO, F. Transição demográfica e desigualdades sociais no Brasil. Revista Brasileira de Estudos da População, v. 25, n. 1, p. 5-26, 2008.

COUTO, E. S.; COUTO, E. S.; CRUZ, I. de M. P. \#fiqueemcasa: educação na pandemia da covid-19. Interfaces Científicas-Educação, v. 8, n. 3, p. 200-217, 2020.

DORNELLES, J. R. Necrocapitalismo e neofascismo em tempos de peste. In: AUGUSTO, C. B.; SANTOS, R. D. dos. Pandemias e pandemônio no Brasil. São Paulo: Editora Tirant Lo Blanch, 2020.

FRAGOSO, S.; RECUERO, R.; AMARAL. Métodos de pesquisa para internet. Porto Alegre: Sulina, 2011. 239 p.

FRANÇA FILHO, A. L. de; ANTUNES, C. da F.; COUTO, M. A. C. Alguns apontamentos para uma crítica da EAD na educação brasileira em tempos de pandemia. Revista Tamoios, v. 16, n. 1, 2020. 
LAZARETTI, L. R.; TEIXEIRA, F. O.; OLIVEIRA, S. V. de. Desigualdades socioeconômicas e demográficas nos municípios do Rio Grande do Sul/Brasil: um índice de vulnerabilidade à pobreza. Urbe, Rev. Bras. Gest. Urbana, Curitiba, v. 11, 2019.

NASCIMENTO, M. L. do; CUNHA, F. L. da; VICENTE, L. M. D. A desqualificação da família pobre como prática de criminalização da pobreza. Revista Psicologia Política, v. 7, n. 14, 2007.

MATA, N. T.; SILVEIRA, L. M. B. da; DESLANDES, S. F. Família e negligência: uma análise do conceito de negligência na infância. Ciência \& Saúde Coletiva, v. 22, p. 2881-2888, 2017.

MELO, B. D.; LIMA, C. C.; MORAES, C. L. D.; ANDRADE, C. B.; PEREIRA, D. R.; SOUZA, E. R. D.; NJAINE, K. Saúde mental e atenção psicossocial na pandemia COVID-19: violência doméstica e familiar na COVID-19. Rio de Janeiro: Fiocruz, 2020. Cartilha. 22 p.

MOREIRA, E. S.; LIMA, E. de O.; BRITO, R. de O. Estudo comparado das políticas públicas educacionais de inclusão digital: Brasil e Uruguai. Revista da Faculdade de Educação, v. 32, n. 2, p. 17-41, 2020.

MOLL, J. Reflexões acerca da educação para a superação da extrema pobreza: desafios da escola de tempo completo e de formação integral. In: CAPELLO, T.; FALCÃO, T.; COSTA, P. V. da (org.). 0 Brasil sem miséria. Brasília 2014.

OLIVEIRA, F. da C.; ROCHA, J. P. D. da C.; NASCIMENTO, I. F. G.; NAIFF, L. A. M.; ÁVILA, R. F.de. Novas páginas de pesquisa em Psicologia Social: o fazer pesquisa na/da internet. Psicologia e Saber Social, v. 6, n. 2, p. 186-204, 2017.

SILVA, E. O.; AMPARO-SANTOS, L.; SOARES, M. D. Alimentação escolar e constituição de identidades dos escolares: da merenda para pobres ao direito à alimentação. Cadernos de Saúde Pública, v. 34, p. e00142617, 2018.

SILVEIRA, S. A. da. Interações públicas, censura privada: o caso do Facebook. História, Ciências, Saúde-Manguinhos, v. 22, p. 1637-1651, 2015. 
1 Doutora em Educação (Psicologia da Educação) pela Pontifícia Universidade Católica de São Paulo; Professora Associada da Universidade Federal de São Paulo - Unifesp no Programa pós-graduação em Educação e curso de Pedagogia; Desenvolve pesquisas no campo da Psicologia da Educação, atuando principalmente nos seguintes temas: Formação de professores, Práticas educativas, Família, Inclusão escolar e Relações étnico-raciais. Membro do Núcleo de estudos Afro-brasileiros - NEAB-Unifesp; Líder do Grupo de Estudo e Pesquisa em Processos Educativos e Perspectiva Histórico-Cultural - GEPPEDH.

E-mail edna.martins@unifesp.br 